\title{
EXPERIMENTAL STUDY AND MATHEMATICAL Modelling of Nonlinear Control Plant
}

\author{
Yevhen Pistun, Roman Fedoryshyn, Volodymyr Zagraj, \\ Hryhoriy Nykolyn \& Roman Kokoshko
}
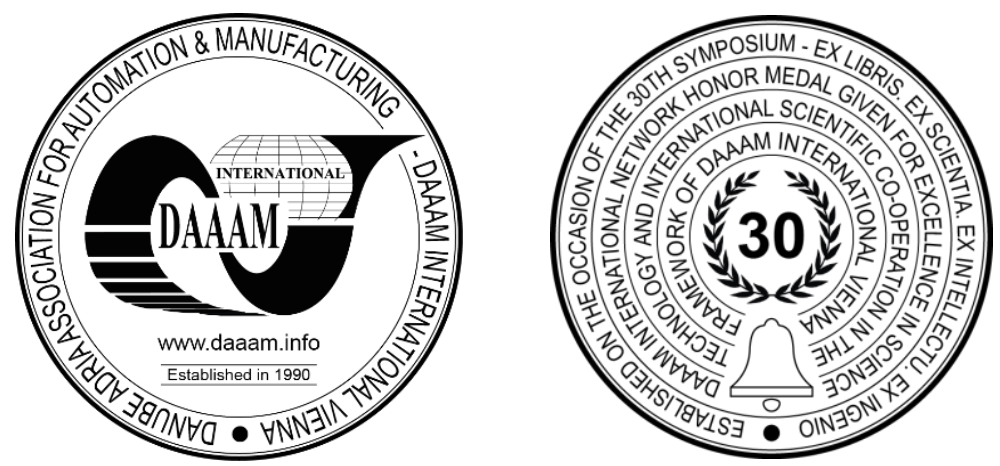

This Publication has to be referred as: Pistun, Y[evhen]; Fedoryshyn, R[oman]; Zagraj, V[olodymyr]; Nykolyn, H[ryhoriy] \& Kokoshko, R[oman] (2019). Experimental Study and Mathematical Modelling of Nonlinear Control Plant, Proceedings of the 30th DAAAM International Symposium, pp.0967-0975, B. Katalinic (Ed.), Published by DAAAM International, ISBN 978-3-902734-22-8, ISSN 1726-9679, Vienna, Austria DOI: $10.2507 / 30$ th.daaam.proceedings.134

\begin{abstract}
A nonlinear control plant was studied based on the ball mill for coal milling at a thermal power station. The vibration parameters of the ball mill that define the quality of the milling process were analyzed. The measurement system for defining the quantity of the material in the mill during its operation is presented. The experimental study of the ball mill parameters was carried out. The following parameters were logged and analyzed: vibration acceleration of the front bearing, air mixture temperature at the mill output, differential pressure across the mill. The mathematical model of the ball mill was developed in the form of the system of nonlinear differential equations. The mass and heat conservation laws as well as heat exchange and flow rate equations were applied for developing the model. This model can be applied for studying the variation of such technological parameters as quantity of the material in the mill, air mixture temperature at the mill output and differential pressure across the mill for different technological modes of the ball mill operation. The simulated transient processes were compared to the experimental data.
\end{abstract}

Keywords: Nonlinear model; Ball mill; Vibration; Coal milling.

\section{Introduction}

The control plants with nonlinear static and dynamic characteristics can often be found in various fields of industry (thermal power engineering, oil and gas, food, pharmaceutical industry etc.). The nonlinear behaviour is usually caused by the peculiarities of the processes that take place in the plant. These might be the heat or mass exchange processes or hydro-gas-dynamic processes. Investigation of nonlinear plants is an important step on the way to creating the control systems for such plants in order to improve their efficiency, productivity and reliability [1]-[3].

The ball mill with nonlinear static and dynamic characteristics is the plant under investigation in this paper. Such mills are applied for coal dust preparation at thermal power stations. The coal milling is a technological process with huge energy consumption which leads to high price of the end product. Thus, the electric power consumption for dust preparation at a thermal power station is equal to $25 \%$ of the total amount of electric power consumed by the station for its own needs [4]. That is why it is important to reduce the energy capacity of this technological process. And it can be 
done by developing the appropriate models for adequate description of the ball mills behaviour. Based on these models the high efficiency automatic control systems will be developed. To do this, reliable information on the ball mill parameters such as the degree of the mill loading with the material is needed. On the other hand, the efficient control algorithms are needed to provide the maximum possible productivity of the mill [5].

One more important task during the ball mill control is to provide the reliability of its operation in order to avoid the emergency situations such as balls blockage, air mixture explosion or dust ducts blocking. To solve this problem there should be automatic protection in the ball mill control system for the main parameters (vibration of the mill front bearing, air mixture temperature at the mill output, differential pressure across the mill drum).

By developing the model of the ball mill it will be possible to carry out investigation of the transient processes in various technological modes of operation. It will provide the possibility to define the structure and the parameters of the automatic control system for such a complex plant. And it will also improve the reliability of the ball mill operation.

\section{Analysis of the ball mill vibration parameters that define the quality of the milling process}

The analysis of the ball mill energy flows on the basis of [6]-[8] has shown that there is a definite relation between the energy spent by the balls to excite vibration of the mill body and the amount of the material in the mill drum. Thus the amount of the material in the mill can be found by defining the vibration energy of the mill body.

The interaction of the balls with the mill drum takes place in the form of beats with an impulse nature. Part of the ball energy after each beat is passed to the drum armour in the form of elastic waves. And the smaller the duration of the beat the more energy is passed to the wave process. These waves spread along the mill body and carry the information on the nature of the balls interaction with the mill drum.

The acoustic channel of the vibrations spreading from the balls interaction with the drum to the sensor of vibrations is a complex dynamic system. The best place for mounting the vibrations sensor is the bearing support since all the other parts of the ball mill are rotated continuously and it is difficult to mount the sensor on them.

The results of studying the spectrum characteristics of the vibration velocity and the vibration acceleration for the front and back bearings of SHBM-50 mill are presented in [9]. There is a distinct maximum on these characteristics in the range of frequencies from 2 to $6 \mathrm{kHz}$ (see Fig.1). The height of this maximum varies with the mill productivity: the higher the productivity the lower the maximum.

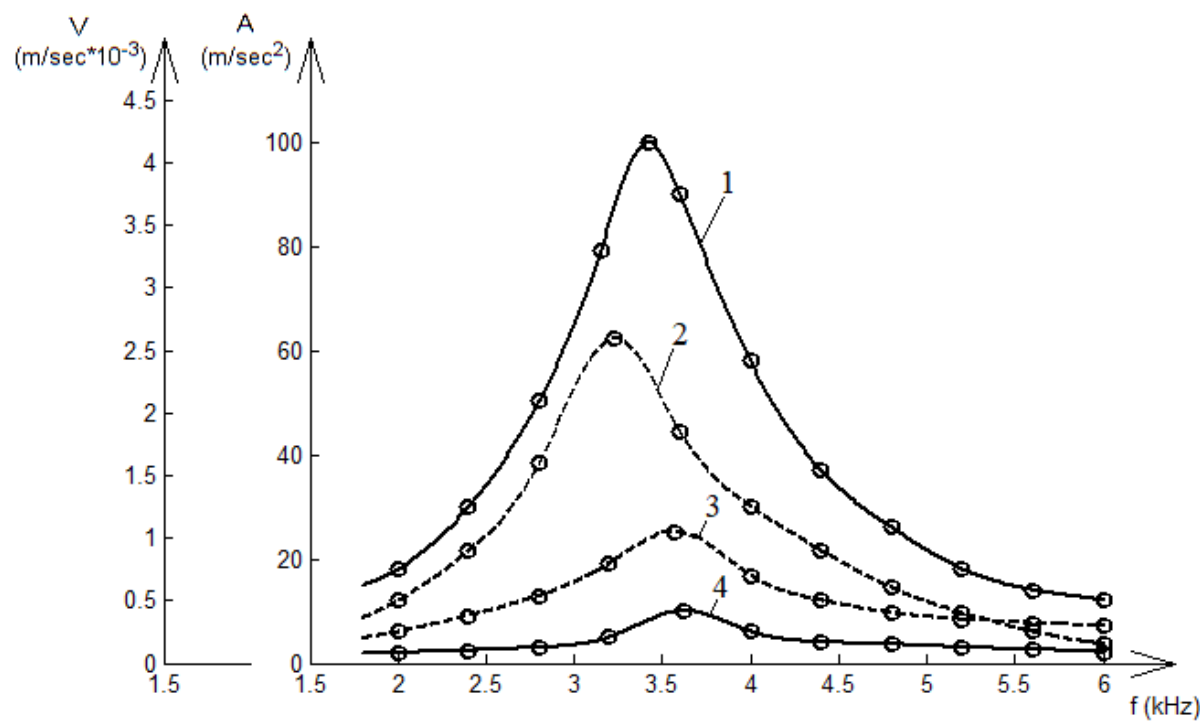

Fig. 1. Spectrum characteristics of the vertical component of the vibration velocity $(2,3)$ and the vibration acceleration $(1,4)$ for the front bearing of SHBM-50 mill at zero productivity $(1,2)$ and at maximum productivity $(3,4)$

The root mean square level of the vibration acceleration at different productivities of the mill varies more significantly for the front bearing than for the back one (see Table 1). It can be explained by the fact that the material concentration at the drum input (near the front bearing) varies more significantly than at the output (near the back bearing) at different productivities of the ball mill.

The relation of the root mean square level of the vibration acceleration for the front bearing versus the relative productivity of the mill $\left(\varepsilon=F_{m} / F_{m}{ }^{\text {max }}\right)$ is reversely proportional (see Fig. 2$)$. The values of the vibration acceleration are in the range from 0.5 to $56 \mathrm{~m} / \mathrm{s}^{2}$ for SHBM-50 mill.

Thus the relative productivity of the ball mill can be defined using the root mean square level of the vertical component of the vibration acceleration for the front bearing of the coal mill in the range from 2 to $6 \mathrm{kHz}$. For the maximum productivity of the mill this level is minimal and does not vary any more at further loading of the mill. 


\begin{tabular}{|c|c|c|c|c|}
\hline \multirow{3}{*}{ Mill No. } & \multicolumn{3}{|c|}{ Root mean square level of the vibration acceleration, $\mathrm{m} / \mathrm{s}^{2}$} \\
\cline { 2 - 5 } & \multicolumn{2}{|c|}{ Productivity $0 \mathrm{t} / \mathrm{h}$} & \multicolumn{2}{c|}{ Productivity $40 \mathrm{t} / \mathrm{h}$} \\
\cline { 2 - 5 } & Front bearing & Back bearing & 0.586 & Back bearing \\
\hline 1 & 55.17 & 51.22 & 0.518 & 0.85 \\
2 & 47.09 & 44.02 & 0.55 & 0.77 \\
3 & 49.49 & 45.98 & 0.63 & 0.89 \\
4 & 57.62 & 53.11 & 0.48 & 0.68 \\
5 & 46.29 & 39.73 & \\
\hline
\end{tabular}

Table 1. The root mean square level of the vibration acceleration at different productivities of the ball mill for the front bearing and back bearing

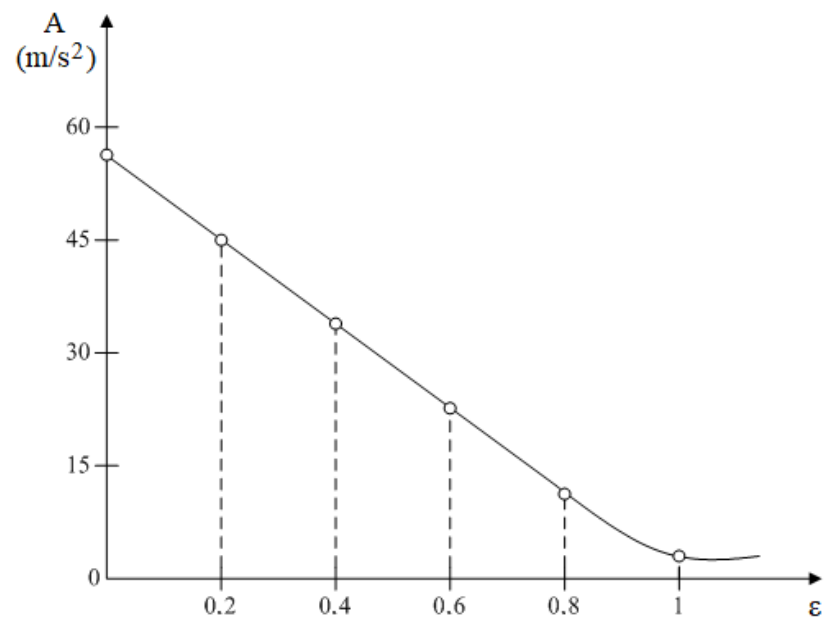

Fig. 2. The root mean square level of the vibration acceleration for the front bearing versus the relative productivity of SHBM-50 mill

\section{Experimental study of the ball mill operation}

\subsection{The measurement system for defining the degree of the mill loading with the material}

The measurement system for defining the degree of the mill loading with the material consists of a vibration sensor, an amplification block, a normalizing block and other elements. The system measures the vertical component of the vibration acceleration in the range from 2 to $10 \mathrm{kHz}$.

The piezo-ceramic accelerometer $\mathrm{ABC} 017-003$ is used as a vibration sensor 1 (see Fig.3). Its range of measurement is from 20 to $10000 \mathrm{~Hz}$. The transfer coefficient is $0.4 \mathrm{mVs}^{2} / \mathrm{m}$ and the capacity is $1200 \mathrm{pF}$. The amplification block 2 consists of the primary amplifier 3, the band-pass filter 4 and the power amplifier 5 . The primary amplifier 3 serves to bring the high-capacity output resistance of the piezo-ceramic accelerometer 1 into conformance with the resistance of the band-pass filter 4 . The amplifier 3 is made of the alternating voltage amplifier with high input resistance.

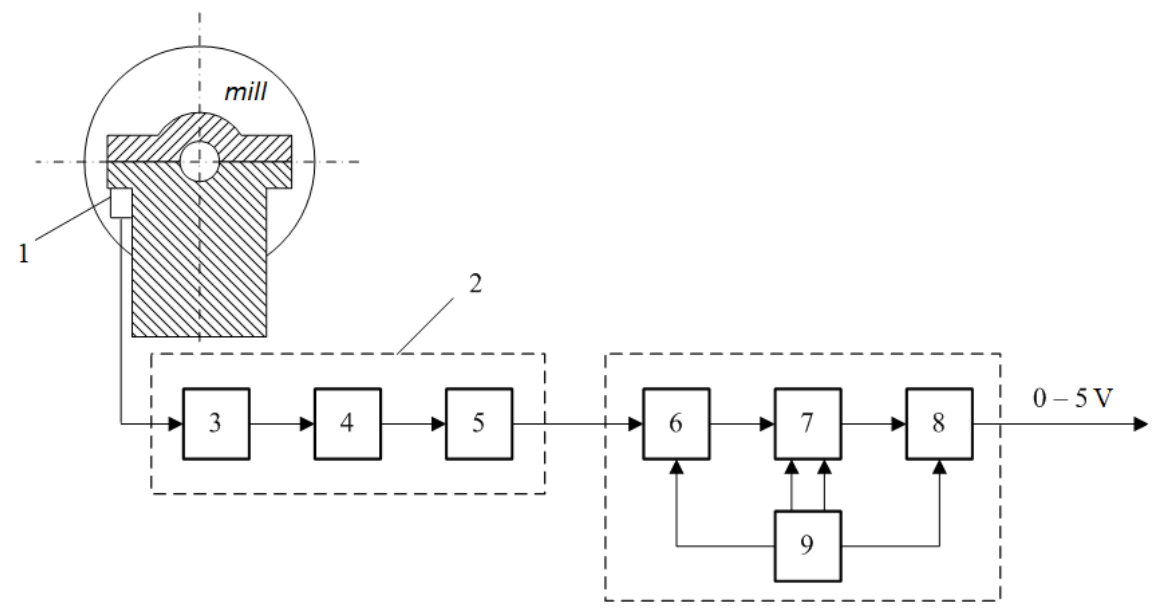

Fig. 3. Diagram of the measurement channel for defining the degree of the mill loading with the material 
There is a passive band-pass filter 4 in the measurement channel with the band width from 2 to $8 \mathrm{kHz}$ in order to get the useful signal from the vibration accelerometer which carries the information on the mill loading with the material. To achieve the accuracy of the vibro-acceleration measurement in the specified range of frequencies the filter circuit is designed in such a way that sufficient attenuation of the signal is provided outside the pass band and there is a slight nonuniformity within the pass band.

After the power amplifier 5 the signal goes to the normalizing amplifier 6, then to the galvanic isolation block 7 and to the block 8 for amplification to the normalized range. Block 9 provides power supply for all the elements with galvanic isolation of voltages. The normalized output signal goes to the microprocessor controller.

\subsection{Experimental data on the transient processes in the mill}

The experimental study of the transient processes was carried out at a thermal power station during the coal milling by means of the ball mill with the parameters specified in Table 2. The obtained transient processes are presented in Fig.4. The air mixture temperature at the mill output, vibration of the front bearing support and differential pressure across the mill are dimensionless signals in the range from 0 to 255 (ADC output). The temperature sensor was calibrated in the range from 0 to $100{ }^{\circ} \mathrm{C}$, the vibration sensor - from 0 to $100 \%$, the differential pressure sensor - from 0 to $5000 \mathrm{~Pa}$.

\begin{tabular}{|l|c|}
\hline \multicolumn{1}{|c|}{ Name of parameter } & Value \\
\hline Internal diameter of the drum (with no lining), mm & 2400 \\
\hline Internal length of the drum (with no lining), mm & 4000 \\
\hline Nominal frequency of the drum rotation, r/m & 21.9 \\
\hline Balls mass, t & 50 \\
\hline Installed power of the electric drive, $\mathrm{kW}$ & 1600 \\
\hline Frequency of the electric drive rotor rotation, r/m & 100 \\
\hline Power supply voltage for the electric drive, V & 6000 \\
\hline $\begin{array}{l}\text { Mass of the mill without the electric equipment, base fitting, mechanical devices and balls noise } \\
\text { isolation, t, not more than }\end{array}$ & 95 \\
\hline Nominal productivity, $\mathrm{t} / \mathrm{h}$ & 25 \\
\hline
\end{tabular}

Table 2. Parameters of the ball mill under investigation

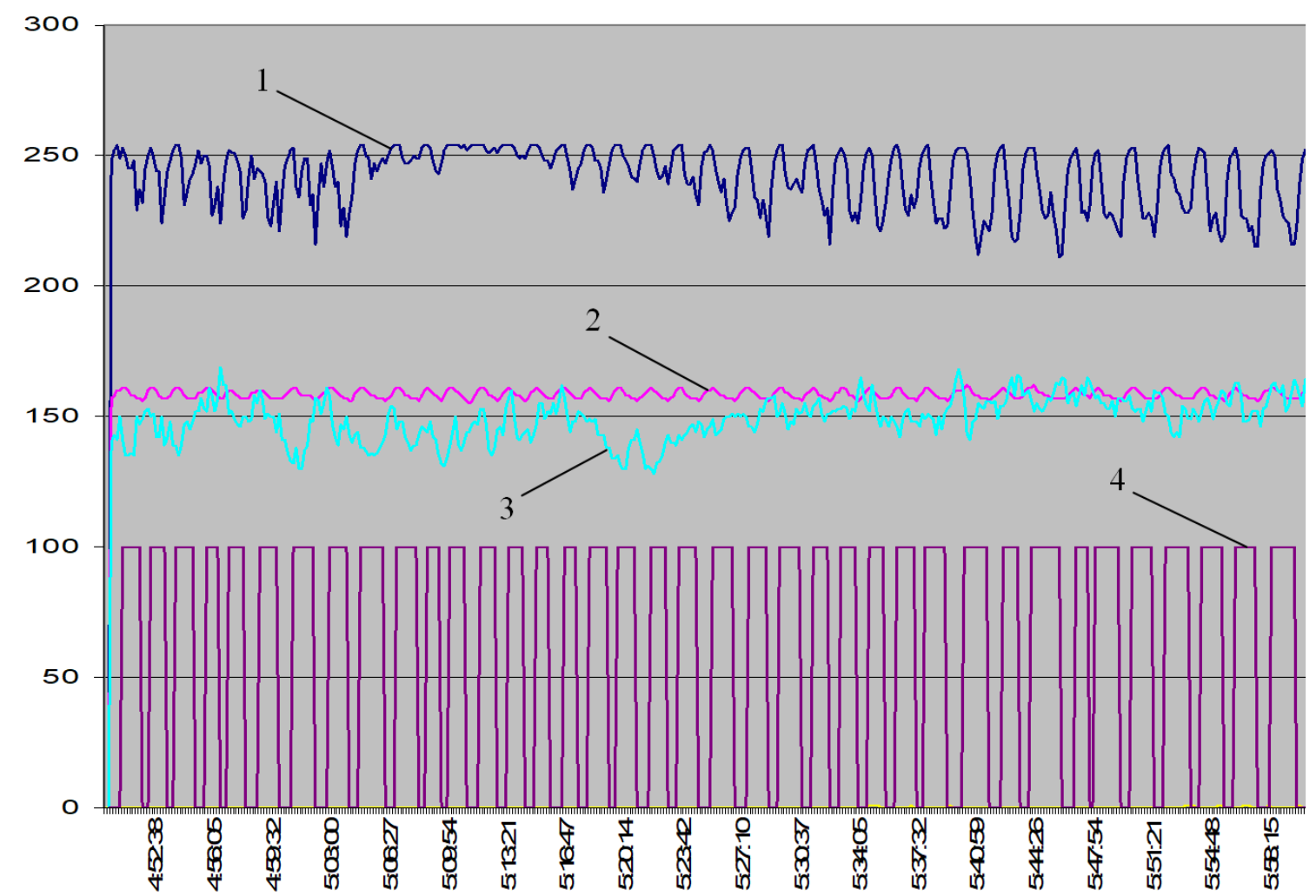

Fig. 4. Experimental transient processes of the main technological parameters (ADC outputs) during ball mill operation: 1 - vibro-acceleration of the front bearing; 2 - air mixture temperature at the mill output; 3 - differential pressure across the mill drum; 4 - raw coal supply to the mill 
As we can see from Fig.4, when supplying the coal to the mill, the front bearing vibration and the temperature of the air mixture at the mill output decrease. This decrease in the vibration shows that the amount of the coal in the mill was increased, since the relation between these two parameters is reversely proportional (see Fig.2).

After scaling the experimental signals according to the ranges of measurement the curves in Fig.5 were obtained.

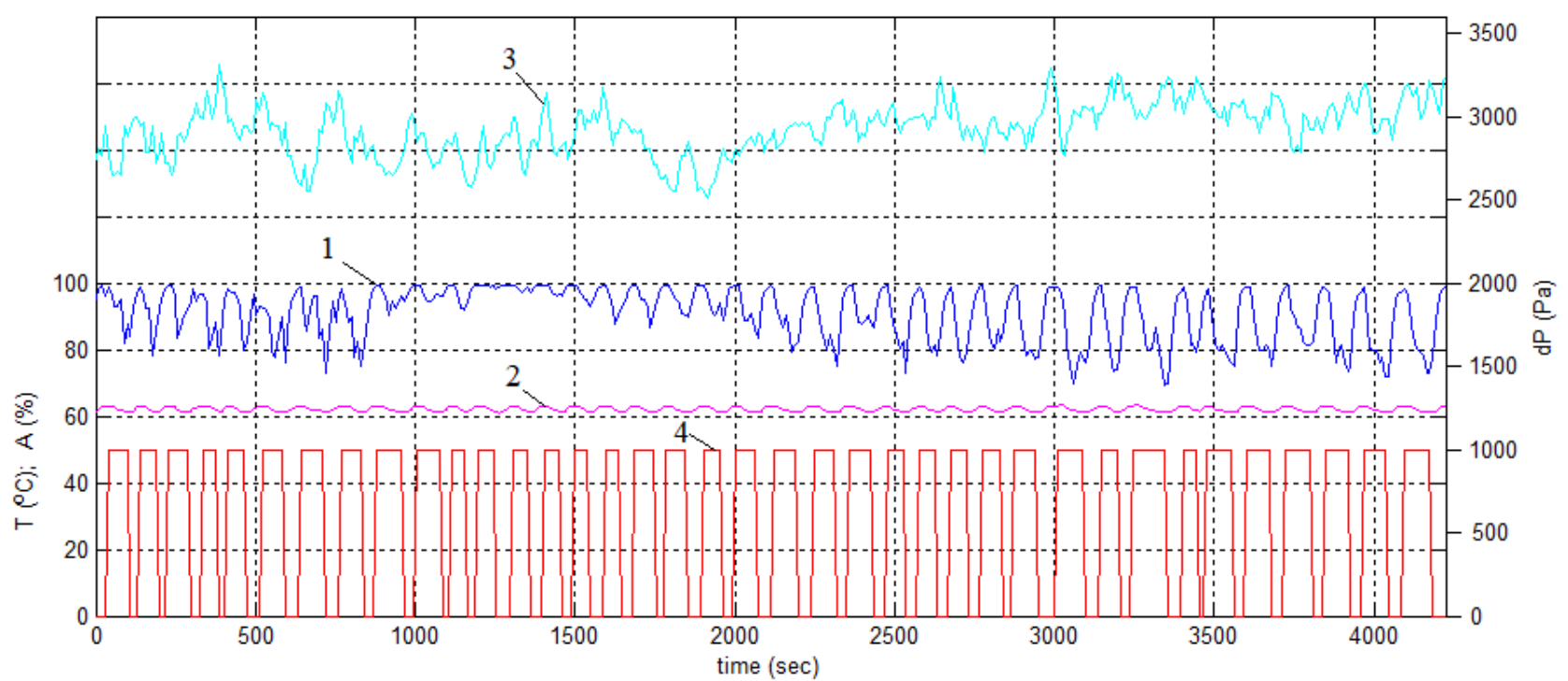

Fig. 5. Experimental transient processes of the main technological parameters scaled according to the ranges of measurement: 1 - vibro-acceleration of the front bearing $(\%) ; 2$ - air mixture temperature at the mill output $\left({ }^{\circ} \mathrm{C}\right)$; 3 - differential pressure across the mill drum $(\mathrm{Pa}) ; 4$ - coal supply to the mill

Taking into account the reverse proportional relation between the vibration signal and the mill loading (the amount of the coal in the mill) the curves of the loading and the coal supply were built (see Fig.6).

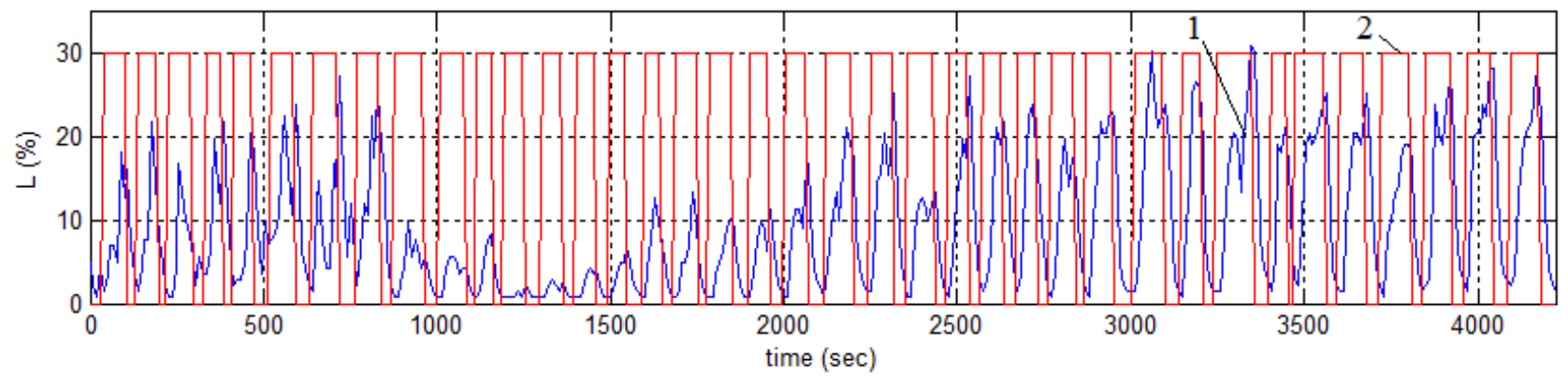

Fig. 6. Experimental data on the ball mill loading (1) and the coal supply to the mill (2)

The experimental data presented above was applied for verification of the adequacy of the developed mathematical model of the ball mill.

\section{Mathematical model of the ball mill}

\subsection{Relation between the technological parameters of the ball mill}

The structural diagram of relation between the technological parameters of the ball mill is presented in Fig.7. The following conclusions can be made on the basis of this diagram:

The mill productivity $\left(F_{m}\right)$ depends on the raw coal flow rate $\left(F_{r}\right)$, return from the separator $\left(F_{s}\right)$, hot and cold air flow rates $\left(F_{h}, F_{c}\right)$ as well as on the frequency of the drum rotation $(n)$, strength of the coal $(\delta)$, moisture content in the raw coal $\left(W_{r}\right)$, initial dimensions of the raw coal $\left(d_{r}\right)$, volume of the mill drum $(V)$, diameter of the mill drum $(D)$, weight of the balls $\left(G_{b}\right)$, weight of the coal $\left(G_{r}\right)$ and diameter of the balls $\left(D_{b}\right)$.

The final dimensions of the milled coal $\left(d_{m}\right)$ depends on the strength of the coal $(\delta)$, weight of the coal $\left(G_{r}\right)$, initial dimensions of the raw coal $\left(d_{r}\right)$, hot air flow rate $\left(F_{h}\right)$ and raw coal flow rate $\left(F_{r}\right)$.

The moisture content in the coal dust $\left(W_{d}\right)$ depends on the relative humidity of hot and cold air $\left(h_{h}, h_{c}\right)$, moisture content in the raw coal $\left(W_{r}\right)$, hot and cold air temperatures $\left(T_{h}, T_{c}\right)$, raw coal flow rate $\left(F_{r}\right)$ and hot air flow rate $\left(F_{h}\right)$. 


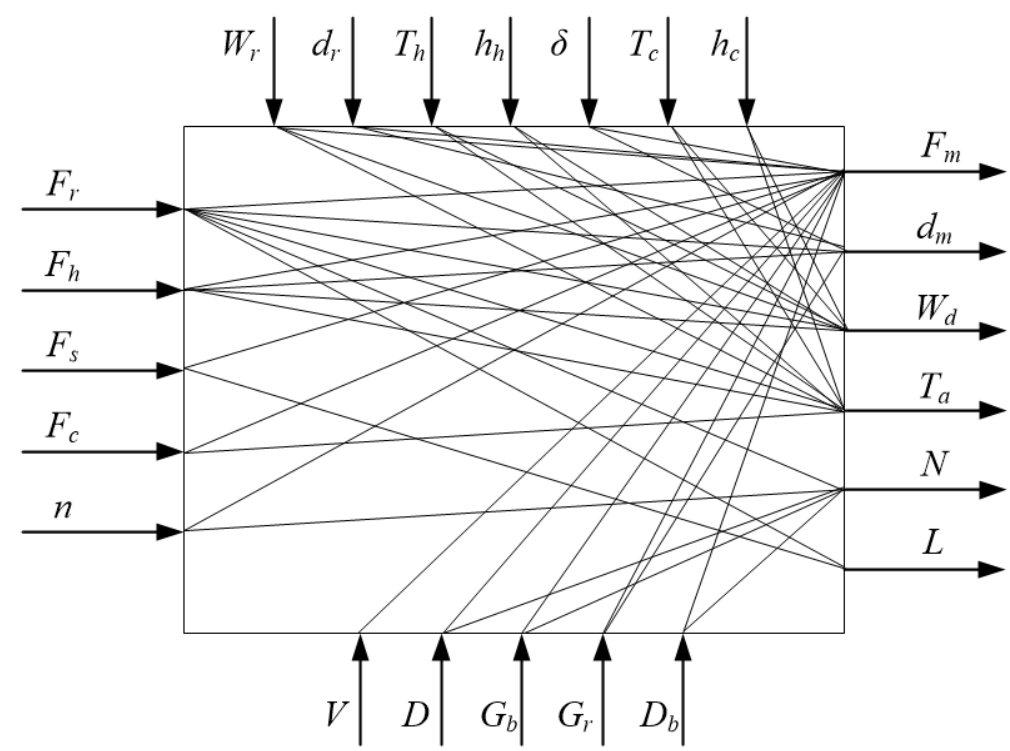

Fig. 7. Structural diagram of relation between the technological parameters of the ball mill

The air mixture temperature $\left(T_{a}\right)$ depends on the hot and cold air temperatures $\left(T_{h}, T_{c}\right)$, relative humidity of hot and cold air $\left(h_{h}, h_{c}\right)$, moisture content in the raw coal $\left(W_{r}\right)$, raw coal flow rate $\left(F_{r}\right)$, hot and cold air flow rates $\left(F_{h}, F_{c}\right)$.

The power consumption $(N)$ depends on the diameter of the mill drum $(D)$, weight of the balls $\left(G_{b}\right)$, diameter of the balls $\left(D_{b}\right)$, raw coal flow rate $\left(F_{r}\right)$ and the frequency of the drum rotation $(n)$.

The quantity of coal in the mill $(L)$ depends on the raw coal flow rate $\left(F_{r}\right)$ and return from the separator $\left(F_{s}\right)$.

In order to develop the mathematical model of the ball mill, a simplified diagram of the relation between the technological parameters was applied (see Fig.8).

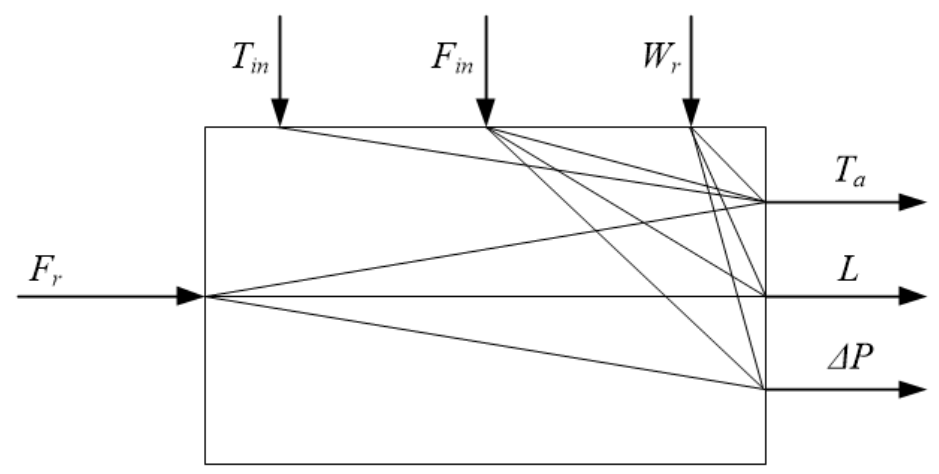

Fig. 8. Simplified diagram of relation between the technological parameters of the ball mill

At practice, the raw coal feeding to the mill $\left(F_{r}\right)$ is controlled on the basis of the air mixture temperature at the mill output $\left(T_{a}\right)$. All the other measured signals act as restrictions for protecting the mill during its operation. The mathematical model of the ball mill should implement the relation of such output parameters as the air mixture temperature at the mill output $\left(T_{a}\right)$, the mill loading with the coal $(L)$ and the differential pressure across the mill $(\Delta P)$ with the following input parameters:

- raw coal flow rate (control action, $F_{r}$ );

- air temperature at the mill input (disturbance, $T_{\text {in }}$ );

- air flow rate at the mill input (disturbance, $F_{i n}$ );

- moisture content of the raw coal (disturbance, $W_{r}$ ).

\subsection{Development of the mathematical model of the ball mill}

Mathematical modeling of the processes in the ball mills was studied in the works [10]-[12]. The following models are presented in these works: diffusion model, ideal displacement and ideal mixing models, cell model etc. The models in these works are theoretical and there is no comparison to the results of experimental study of the ball mills.

Our goal is to develop a mathematical model that will provide the results of modeling close to the obtained experimental data. For this purpose a structural diagram of the ball mill was suggested (see Fig.9). 


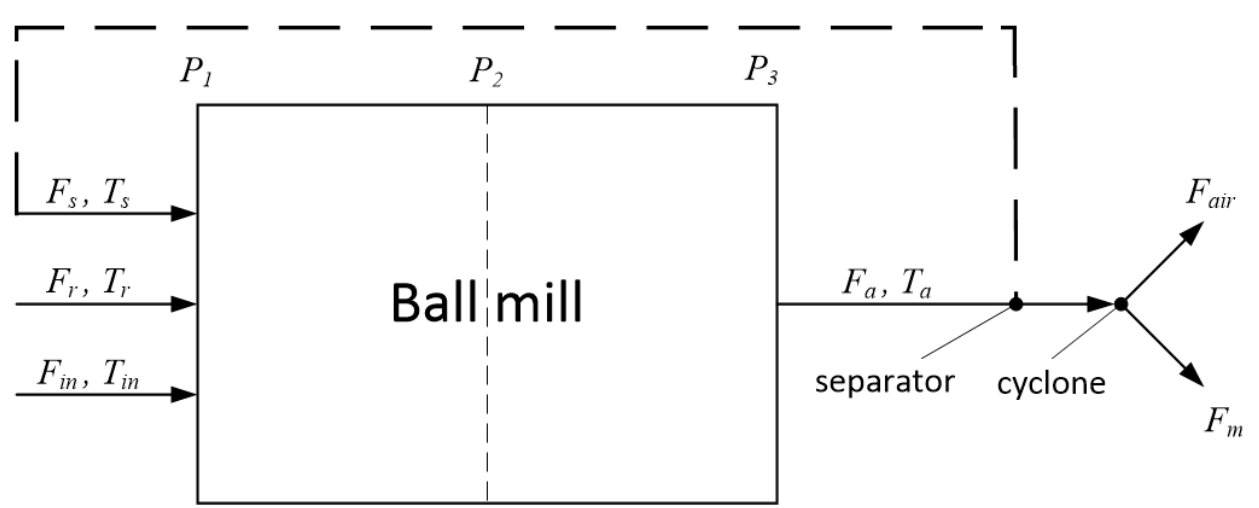

Fig. 9. Structural diagram of the ball mill for development of its mathematical model

At the result of application of the mass and heat conservation laws as well as heat exchange and flow rate equations, after conversions and substitutions, the following mathematical model of the ball mill was obtained in the form of the system of the differential equations:

$$
\left\{\begin{array}{c}
V \frac{d \rho_{\mathrm{a}}}{d t}=F_{i n} \cdot \rho_{i n}+F_{r}^{m}+0.4 \cdot F_{m}^{m}-F_{\mathrm{a}} \cdot \rho_{\mathrm{a}} ; \\
A \cdot \frac{d F_{i n}}{d t}+F_{i n}^{2}=k^{2} \cdot \frac{P_{1}-P_{2}}{\rho_{\text {in }}} ; \\
A \cdot \frac{d F_{\mathrm{a}}}{d t}+F_{\mathrm{a}}^{2}=k^{2} \cdot \frac{P_{2}-P_{3}}{\rho_{\mathrm{a}}} ; \\
F_{m}^{m}=\left(F_{a}\left(t-\tau_{m}\right) \cdot \rho_{\mathrm{a}}\left(t-\tau_{m}\right)-F_{a .0} \cdot \rho_{\mathrm{a} .0}\right) / 1.4 ; \\
\Delta P=P_{1}-P_{2}+\frac{F_{\mathrm{a}}^{2}\left(t-\tau_{m}\right) \cdot \rho_{\mathrm{a}}^{2}\left(t-\tau_{m}\right)}{k^{2} \cdot \rho_{i n}} ; \\
L=\left(\rho_{a}-\rho_{a .0}\right) \cdot V ; \\
\frac{d \mathrm{~T}_{\mathrm{a}}}{d t} \cdot V \cdot \rho_{\mathrm{a}} \cdot c_{P a}=T_{i n} \cdot c_{P i n} \cdot F_{i n} \cdot \rho_{i n}+T_{r} \cdot c_{P r} \cdot F_{r}^{m}+ \\
+0.4 \cdot \frac{T_{a}+T_{r}}{2} \cdot c_{P r} \cdot F_{m}^{m}- \\
-T_{\mathrm{a}} \cdot c_{P a} \cdot F_{a} \cdot \rho_{\mathrm{a}}-K_{m} \cdot S_{m} \cdot\left(T_{\mathrm{a}}-T_{a m b}\right),
\end{array}\right.
$$

where $V$ is the internal volume of the mill drum $\left(\mathrm{m}^{3}\right) ; \rho_{a}$ is the dencity of air mixture $\left(\mathrm{kg} / \mathrm{m}^{3}\right) ; P_{1}$ is the pressure at the mill input $(\mathrm{Pa}) ; P_{2}$ is the pressure in the middle of the mill $(\mathrm{Pa}) ; P_{3}$ is the pressure at the mill output $(\mathrm{Pa}) ; F_{r}{ }^{m}$ is the raw coal flow rate at the mill input $(\mathrm{kg} / \mathrm{s}) ; F_{\text {in }}$ is the air flow rate at the mill input $\left(\mathrm{m}^{3} / \mathrm{s}\right) ; F_{a}$ is the air mixture flow rate at the mill output $\left(\mathrm{m}^{3} / \mathrm{s}\right) ; F_{m}$ is the milling productivity of the ball mill $(\mathrm{kg} / \mathrm{s}) ; \tau_{m}$ is the transport delay of the coal movement through the mill drum $(\mathrm{s}) ; c_{P a}$ is the heat capacity of the air mixture at the output $(\mathrm{J} /(\mathrm{kg} \cdot \mathrm{K})) ; c_{P i n}$ is the heat capacity of the air at the input of the mill $(\mathrm{J} /(\mathrm{kg} \cdot \mathrm{K})) ; T_{r}$ is the raw coal temperature at the input $(\mathrm{K}) ; T_{\text {in }}$ is the air temperature at the mill input $(\mathrm{K}) ; T_{s}$ is the temperature of the coal returning from the separator $(\mathrm{K}) ; T_{a}$ is the air mixture temperature at the mill output $(\mathrm{K}) ; T_{a m b}$ is the ambient air temperature $(\mathrm{K})$.

There are two nonlinear differential equations in the developed mathematical model, i.e. the second and the third equation (flow rate equations). The model implements the relation of air mixture temperature at the mill output ( $\left.T_{a}\right)$, the mill loading with the coal $(L)$ and the differential pressure across the mill $(\Delta P)$ with a number of input values with taking into account the technological and constructional parameters of the ball mill.

\subsection{Modelling of transient processes}

The transient processes were simulated on the basis of the developed mathematical model for the ball mill with the parameters specified in Table 2. The simulation was carried out for the operating mode in which the experimental data were obtained (see Fig.5, Fig.6). These experimental data were applied for verifying the adequacy of the developed mathematical model. Since there is noise in the obtained experimental data and the random component is significant in the logged values, the transient processes were averaged to reduce the influence of the noise and to get the useful signals based on the experimental data. The comparison of the averaged experimental and simulated transient processes of the main technological parameters (air mixture temperature at mill output, mill loading with the coal and differential pressure across the mill drum) at variable flow rate of raw coal at mill input is presented in Fig.10-Fig.12. 


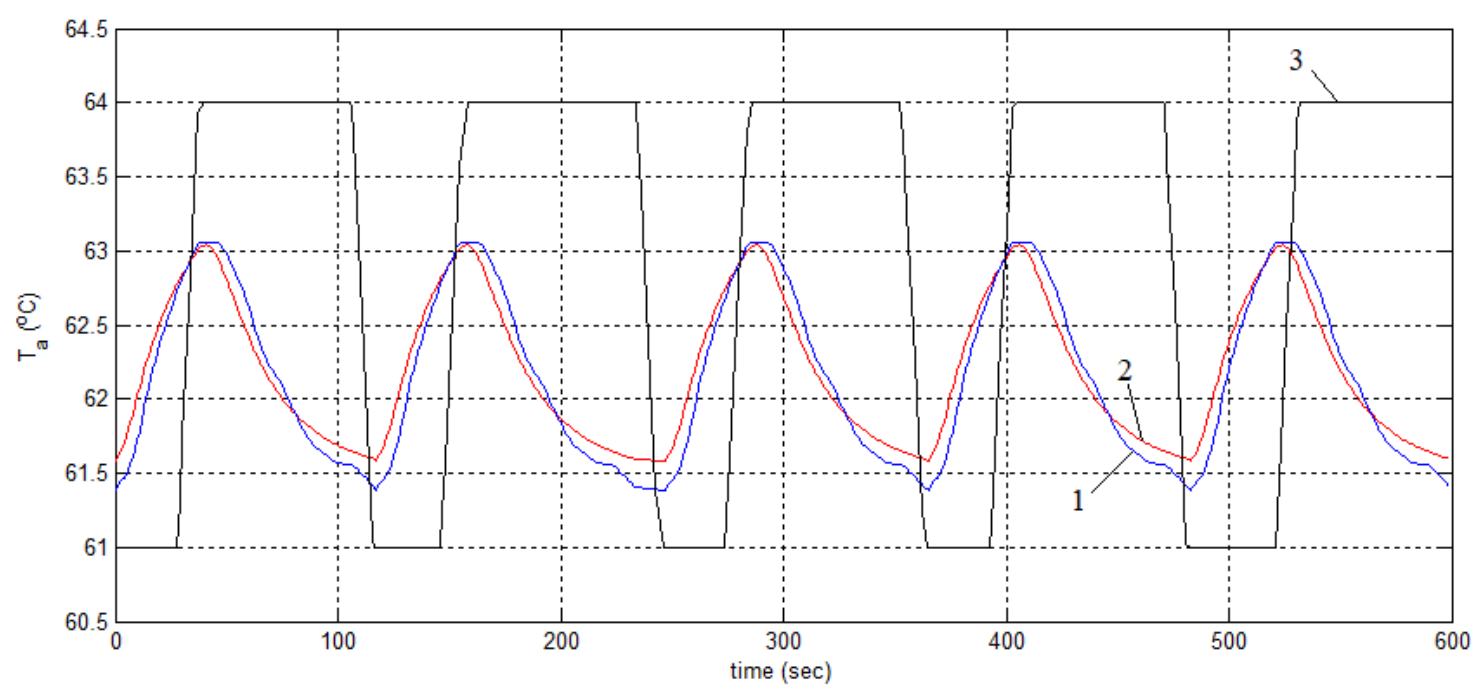

Fig. 10. Comparison of the averaged experimental (curve 1) and simulated (curve 2) transient process of the air mixture temperature variation at variable flow rate of raw coal at mill input (curve 3)

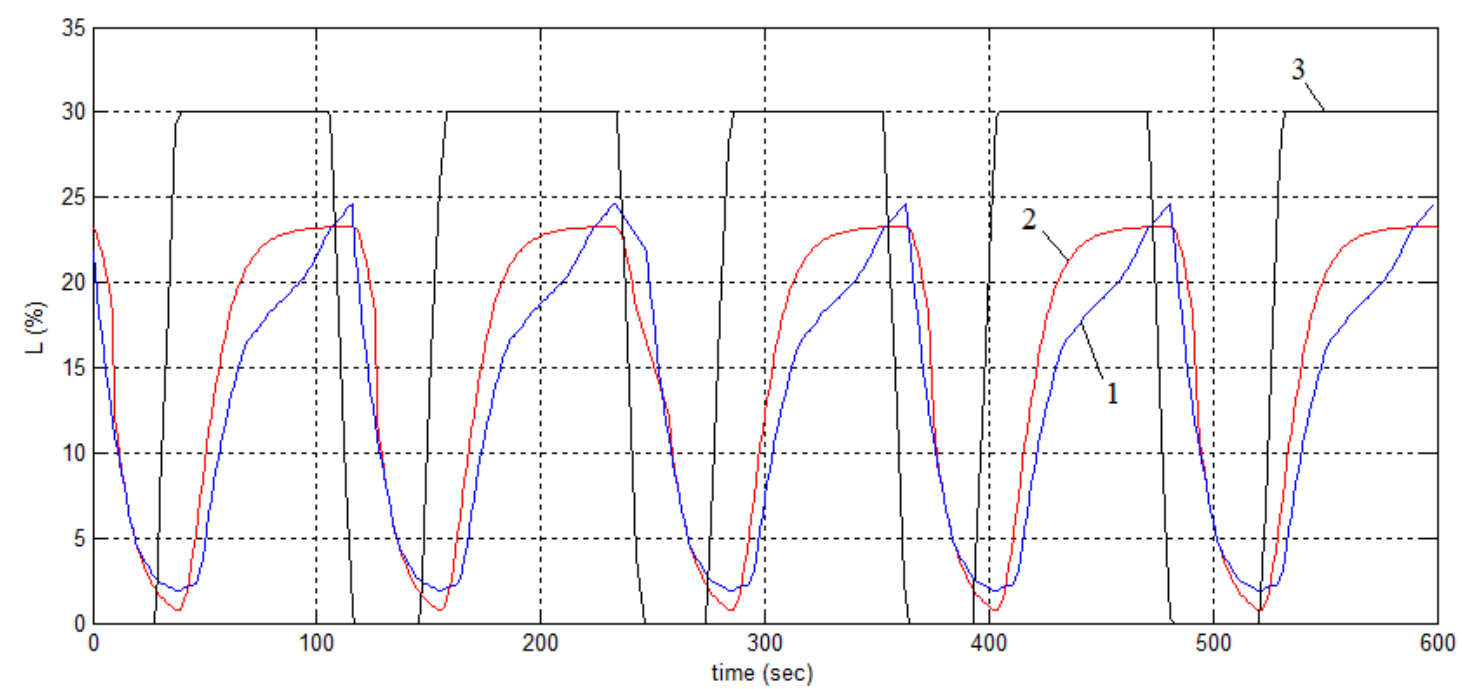

Fig. 11. Comparison of the averaged experimental (curve 1) and simulated (curve 2) transient process of the mill loading variation at variable flow rate of raw coal at mill input (curve 3)

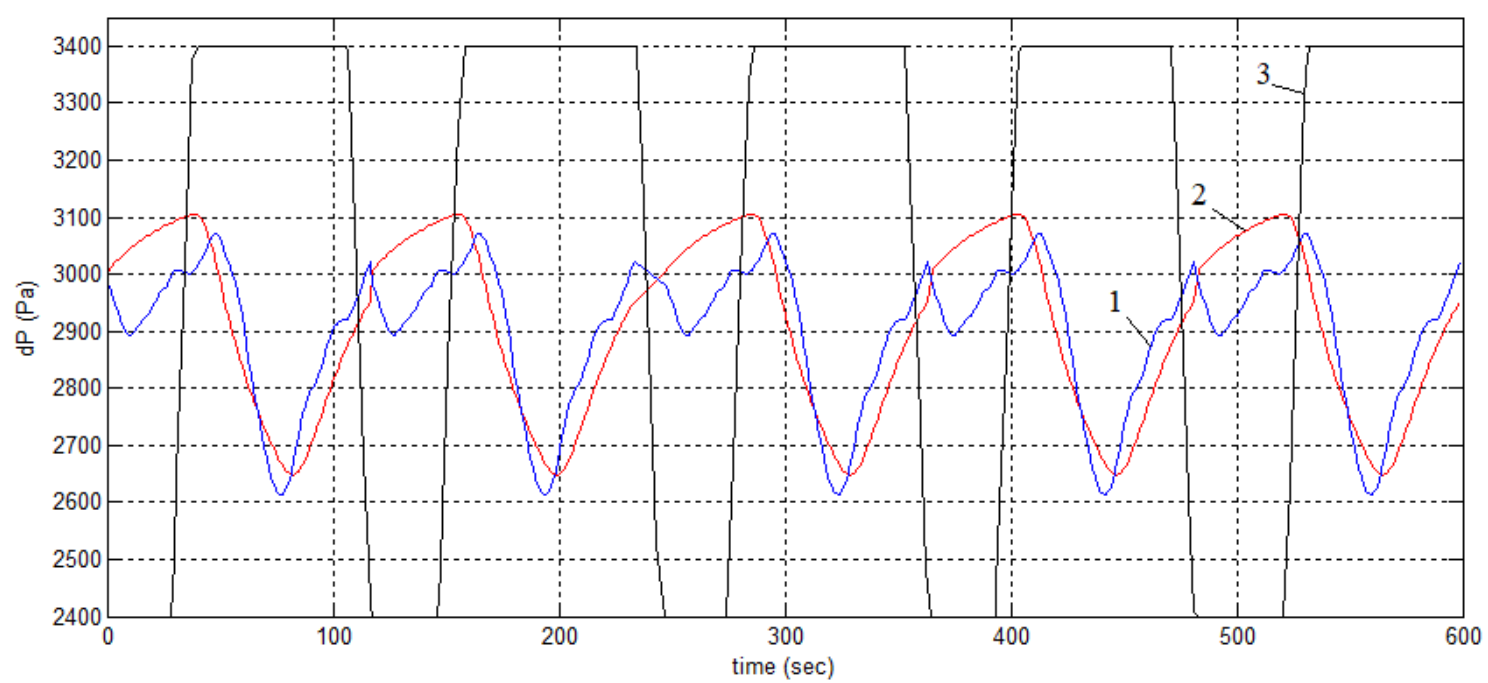

Fig. 12. Comparison of the averaged experimental (curve 1) and simulated (curve 2) transient process of the differential pressure across the drum at variable flow rate of raw coal at mill input (curve 3) 
The relative reduced errors of the simulated transient processes with respect to the averaged experimental processes were calculated. For the air mixture temperature variation this error is 5.0 \%, for the mill loading signal it is $7.4 \%$, and for the differential pressure across the mill drum the error equals $11.2 \%$.

Based on the comparison of the simulated transient processes with the experimental ones we can make a conclusion that the developed mathematical model of the ball mill provides sufficient accuracy of the transient processes modelling. The model can be applied at practice for studying the ball mill operation in various modes as well as for development of automatic control algorithms for coal milling process at thermal power plants.

\section{Conclusion}

On the basis of the accomplished investigation, the ball mill was analyzed as a control plant. It was found that there is a definite relation between the energy spent by the balls for igniting the vibrations of the mill body and the amount of the material in the mill drum. It means that by defining the vibration energy of the mill body the amount of the material in the mill can be defined.

The spectrum characteristics of the vibration velocity and vibration acceleration for the front and back bearings of SHBM-50 mill were analyzed. Based on this analysis it was found that the relative productivity of the ball mill can be defined using the root mean square level of the vertical component of the vibration acceleration for the front bearing of the coal mill in the range from 2 to $6 \mathrm{kHz}$. For the maximum productivity of the mill this level is minimal and does not vary any more at further loading of the mill.

The mathematical model of the ball mill was developed in the form of the system of nonlinear differential equations Mass and heat conservation laws as well as heat exchange and flow rate equations were applied for this purpose. Using the developed model, the transient processes of the main technological parameters in the ball mill were simulated and compared to the obtained experimental data. The developed model of the ball mill provides good accuracy at modelling such parameters as the air mixture temperature at the mill output, the mill loading with the coal and the differential pressure across the mill drum. The model can be applied at practice for studying the ball mill operation in various modes as well as for development of automatic control algorithms for coal milling process at thermal power plants.

\section{References}

[1] Macku, L[ubomir] \& Novosad, D[avid] (2017). Influence of Online Identification Methods on the Nonlinear Process Control, Proceedings of the 28th DAAAM International Symposium, pp.0216-0223, B. Katalinic (Ed.), Published by DAAAM International, ISBN 978-3-902734-11-2, ISSN 1726-9679, Vienna, Austria

[2] Opalka, J. \& Hubka, L. (2015), "Nonlinear state and unmeasured disturbance estimation for use in power plant superheaters control", Procedia Engineering, pp. 1539

[3] Filaretov, V[ladimir]; Zhirabok, A[lexey]; Zuev, A[lexander] \& Protcenko, A[leksandr] (2016). Identification of Faults in Nonlinear Dynamic Systems, Proceedings of the 26th DAAAM International Symposium, pp.0470-0477, B. Katalinic (Ed.), Published by DAAAM International, ISBN 978-3-902734- 07-5, ISSN 1726-9679, Vienna, Austria

[4] Pistun, Y., Zagraj, V. \& Skobalo, A. (2002). Automatic control and optimization of ball mills, Proc. of VIII Forum of Power Engineers, Techn. Univ. of Opole, May 29-31, 2002, ISBN 83-88492-04-7, Kabza, Z. (Ed.), pp. 575-581, Publ.House of Tech. Univ. of Opole, Opole, Poland

[5] Fedoryshyn, R.; Nykolyn, H.; Zagraj, V. \& Pistun, Y. (2012). The improved system for automation and optimization of solid material grinding by means of ball mills. Annals of DAAAM for 2012 \& Proceedings of the $23 \mathrm{rd}$ International DAAAM Symposium, ISBN 978-3-901509-91-9, ISSN 2304-1382, CDROM version, pp.053-056, Editor B. Katalinic, Published by DAAAM International, Vienna, Austria, EU, 2012

[6] Formusatin V. P. (2007) Improvement of dust systems productivity at thermal power stations. - Power stations, No. 6, pp. 1-4

[7] Levit, G. (1991). Production of dust at thermal power stations, Energoatomizdat, ISBN 5-283-00151-2, Moscow, $384 \mathrm{p}$

[8] Bai, Y. \& He, F. (2015), "Modeling on the effect of coal loads on kinetic energy of balls for ball mills", Energies, vol. 8, no. 7, pp. 6859-6880

[9] Druzhbliak O. M., Pistun Y. P., Trus A. I. (1984) Systems for feeding the ball mills. - Power engineering and electrification, No. 8, pp. 29-32

[10] T. Chai, L. Zhai, and H. Yue, (2011). "Multiple models and neural networks based decoupling control of ball mill coal-pulverizing systems," Journal of Process Control, vol. 21, no. 3, pp. 351-366

[11] Feng, L., Yang, F., Zhang, W. \& Tian, H. (2019). "Model Predictive Control of Duplex Inlet and Outlet Ball Mill System Based on Parameter Adaptive Particle Swarm Optimization", Mathematical Problems in Engineering, vol. 2019

[12] Lingfang, S., Jingmiao, S., Yinde, M., Congwei, F., Jibing, R. \& Wei, Y. (2015), "Application research of PID-GPC algorithm in the ball mill system", Open Automation and Control Systems Journal, vol. 7, no. 1, pp. 157-166 